themselves acquired new, inhibitory properties, for that requires the assumption that inhibition is initially localised in sensory cortical areas, and would then have to be propagated to the cortical representation of the unconditioned reflex. Indeed, the fact that physiological inhibition does not irradiate over the cortex is used by Anokhin to establish an even stronger conclusion: since the effects of inhibitory conditioning to one stimulus do generalise to similar stimuli, such conditioning cannot, in fact, be inhibitory at all; its effects must be caused by the excitatory conditioning of an antagonistic motivational state.

Most western psychologists, I think, would agree that this type of argument was radically misconceived. What they will find worse, is the way Anokhin continually shifts back and forth between behavioural and physiological evidence, with no clear recognition of the difference between the nature of the evidence in the two cases. With some effort, one can discern the similarities between Anokhin's behavioural arguments and those familiar to western psychologists. Thus, Anokhin's general analysis stresses the importance of a feedback principle (the action acceptor), whereby discrepancies between behaviour and goal are registered and serve to initiate correcting action. Inhibitory learning is then said to arise when the organism detects an adverse discrepancy between the actual and expected outcome of a trial (as the omission of expected food), and this generates an aversive motivational state which suppresses the organised appetitive activity originally conditioned by the presentation of food. There is an obvious resemblance to the version of frustration theory proposed by Spence, Amsel and others, and Anokhin occasionally adduces behavioural evidence in support of his account, which is gratifyingly similar to that advanced in support of frustration theory. But this is interspersed with neunophysiological evidence, and separated by chapters of neurophysiological analysis, the behavioural implications of which are at best obscure, and at worst patently nonexistent.

As its title suggests, the book is concerned not only with the analysis of conditioning and learning, but also with the biological significance of unconditioned reflexes, and the nature of adaptive systems. Occasional passages in these chapters ring true to a western ear, but it is hard to find many examples of sustained argument or of close interplay between data and theory. It seems depressingly insular to say so, but if there is anything for us to learn from Soviet psychology, it is not apparent from this book.

N. J. Mackintosh

\section{Book of the moth}

The World of Moths. By Michael Dickens and Eric Storey. Pp. 127. (Osprey: London, 1974.) £2.25.

IN a world that contains over 100,000 species, authors who must restrict an introductory book to cover only 100 species have a difficult task. Although there may be a temptation to choose only British species, I am delighted to find that this small, unpretentious book makes those new to the subject, especially young people, immediately aware of what exists in the tropics. It dispels the illusion that moths are "dirty brown things" and although "professionals' will argue that but a few families are represented, with emphasis only on hawk moths ( 30 species) and silk moths (39 species), I think this is a delightful 'starter's book' with a whole page of useful information devoted to each species illustrated. The coloured photographs are splendid and I am sure that, at its modest price, the book will be a favourite Christmas gift.

\section{E. R. Laithwaite}

\section{Radiation, ecology, and Soviet concern}

Radioecology. Edited by V. M. Klechkovskii, G. G. Polikarpov, and R. M. Aleksakhin. (A Halsted Press Book.) Pp. xii +371 . (Wiley: New York and Toronto; Israel Program for Scientific Translations: Jerusalem and London, 1973.) n.p.

Radioecology began during the 1920 s with studies of the biological effects of ionising radiation on living organisms in regions with high concentrations of natural radionuclides. By the $1950 \mathrm{~s}$ it had become clear, at least to the Soviet Union, that the wider environmental effects of increasing radiation levels (especially from atmospheric nuclear testing) were so poorly understood that a vastly enhanced research effort was required. This book, written because the "work done by Soviet scientists has been ignored in published material outside the USSR", reveals just how seriously the Soviet Union takes the problem and how extensive their work has been.

The two fundamental problems in radioecology are to determine how radionuclides migrate within biogeological systems and how ionising radiations affect microorganisms, plants and animals. The 17 chapters describe Soviet researches into the ways that radionuclides (natural and artificial) and radiation behave in soils, forest communities, crops, food chains, natural pastures, wild and farm animals, the fiar north, water, fish, aquatic plants and man. There is also a short discussion about the practical problems associated with the measurement of radioactivity in complex natural environments.

Many of these studies have evidently been undertaken with an eye to the consequences of exploiting nuclear energy for peaceful purposes. The editors see nuclear power taking a "prominent place" in the Soviet Union in the near future and envisage the extensive use of nuclear explosions in mining and construction. This being the case, they argue that an understanding of the ecological effects of radioactive pollution must "play an important role in the drafting of suitable restrictions".

Peter J. Smith

\section{Renewed hope for developmentalbiology}

Experimental Studies of Amphibian Development. By E. Hadorn. Pp. vii + 138. (Springer-Verlag: Berlin, Heidelberg, New York, 1974.) \$8.20.

THIS short and excellent book is a translation from the German, designed "to introduce the reader to experimental research on development".

Developmental biology is experiencing what Professor Hadorn archly describes as a "Period of Renewed Hope" but many would say that it still remains in a delicate condition. One problem is a growing mass of experimental data that is too flexible and provides unconvincing support for too many theories. Another is that we do not know which organisms to concentrate on. The traditional choice has been the Amphibia, which Hadorn makes the subject of his book. Yet his presentation is far from traditional; his method is to avoid the litigious citation of references and to concentrate on describing a series of clean experiments while omitting the messy ones.

Professor Hadorn guides us through the growth of an individual with experimental analysis as we go along. $\mathrm{He}$ mixes deep descriptions of such knotty problems as gastrulation and induction with the light relief of metamorphosis and the mating habits of newts. The book describes many classical experiments and also includes recent discoveries; for instance, we are told that Millipore filters, long used by deluded embryologists as supposed barriers to cell contact, do not act as barriers at all.

The description and diagrams are clear and the subject matter well chosen. In the past, developmental biology has suffered from heavy presentation, but this book offers a delightful contrast.

Peter Lawrence 